\title{
Fibrewise Fuzzy Topological Spaces
}

\author{
Yousif Y. Yousif \\ yoyayousif@yahoo.com \\ yousif.y.y@ihcoedu.uobaghdad.edu.iq \\ Department of Mathematics, College of Education for Pure Science (Ibn Al-Haitham), \\ University of Baghdad
}

Article history: Received 28 September 2020, Accepted 8 November 2020, Published in July 2021 .

Doi: $10.30526 / 34.3 .2681$

\begin{abstract}
We introduce and discuss the modern type of fibrewise topological spaces, namely fibrewise fuzzy topological spaces. Also, we introduce the concepts of fibrewise closed fuzzy topological spaces, fibrewise open fuzzy topological spaces, fibrewise locally sliceable fuzzy topological spaces and fibrewise locally sectionable fuzzy topological spaces. Furthermore, we state and prove several theorems concerning these concepts.
\end{abstract}

Keywords: fuzzy open, FWFTS's, FWCFTS's, FWOFTS's, FW-LSL-FTS's and FW-LSEFTS's.

AMS Subject Classification: 55R70, 54A40, 54C08, 54C10.

\section{Introduction}

The notion of fibrewise topology was introduced by James [6] who studied a good number of concepts and results. In recent times, many researchers studied this notion [1, 7, 16, 17]. Contributions of Yousif and Hussain [10- 12], Yousif and Hussain [13- 15] and Mohammed and Yousif [8] in the field of fibrewise topology and related concepts are important to be mentioned. The fibrewise (written as FW) sets over an explicit set, called the base set, say b. A FW set over $\mathrm{b}$ push back of a set $\mathrm{m}$ jointly with a mapping $\mathrm{P}: \mathrm{m} \rightarrow \mathrm{b}$, called the projection (written as proj.). The subset $m_{b}=P^{-1}(b)$ of $m$ is the fibre over $b$ for every point $b \in b$. Possibly, fibre will be empty since we do not require $\mathrm{P}$ is a surjectve, also, the subset $\mathrm{m}_{\mathrm{b}^{*}}=\mathrm{P}^{-1}\left(\mathrm{~b}^{*}\right)$ as a FW set over $\mathrm{b}^{*}$ for every subset $\mathrm{b}^{*} \subseteq \mathrm{b}$ with the proj. fixed by $\mathrm{P}$. The notation $\mathrm{m} \mid \mathrm{b}^{*}$ is sometime suitable instead of $m_{b^{*}}=P^{-1}(b)$. The Cartesian product $b \times t$, for every set $t$, like a FW set $b$ by the first proj.. 
Definition 1.1. [6] A mapping $\theta: m \rightarrow n$, where $m$ and $n$ are FW sets over $b$, with proj.'s $P_{m}: m$ $\rightarrow \mathrm{b}$ and $\mathrm{P}_{\mathrm{n}}: \mathrm{n} \rightarrow \mathrm{b}$, is said to be FW mapping (written as FW-M) if $\mathrm{P}_{\mathrm{n}}$ o $\theta=\mathrm{P}_{\mathrm{m}}$, or $\theta\left(\mathrm{m}_{\mathrm{b}}\right) \subseteq \mathrm{n}_{\mathrm{b}}$, for every point $b \in b$.

Observe that a FW-M $\theta: \mathrm{m} \rightarrow \mathrm{n}$ over b limited by restriction, a FW-M $\theta: \mathrm{m}_{\mathrm{b}^{*}} \rightarrow \mathrm{n}_{\mathrm{b}^{*}}$ over $\mathrm{b}^{*}$ for every subset $b^{*} \subseteq b$.

Definition 1.2. [6] The fibrewise topology (written as FWT) on a FW set m over a topological space $(b, \Lambda)$ signifies any topology on $\mathrm{m}$ for which the proj. $\mathrm{P}$ is continuous (written as FWTS).

Definition 1.3. [6] Let $m$ and $n$ be FWTS's over $b$, the FW-M $\theta: m \rightarrow n$ is said to be:

(a) continuous if $b \in b$ and for every point $m \in m_{b}$, the pre image of every open set of $\theta(m)$ is an open set of $m$.

(b) open if $b \in b$ and for every point $m \in m_{b}$, the image of every open set of $m$ is an open set of $\theta(\mathrm{m})$.

Definition 1.4. [6] The FWTS $(m, \tau)$ over $(b, \Lambda)$ is said to be:

(a) FW closed (written as FWC) if the proj. $\mathrm{P}$ is a closed mapping.

(b) FW open (written as FWO) if the proj. $\mathrm{P}$ is a open mapping.

The concept of fuzzy sets was introduced by Zadeh [18]. The idea of fuzzy topological spaces was introduced by Chang [2]. Different aspects of such spaces have been developed by several investigators. In this work, by $(\mathrm{m}, \tau)$ we will denote a fuzzy topological space (written as FTS)

Definition 1.5. [2] A mapping $\theta:(\mathrm{m}, \tau) \rightarrow(\mathrm{n}, \sigma)$ is said to be fuzzy continuous if the pre image of every fuzzy open set of $n$ is a fuzzy open set in $m$.

This paper is mixed and devoted to the development of the theory of fibrewise topological spaces and fuzzy topological spaces. For other notions or notations not defined here, we follow closely in $[2,3,4,5,6,9,18]$.

\section{Fibrewise fuzzy topological spaces}

We will introduce the ideas of fibrewise fuzzy topological spaces, several properties on the obtained fibrewise concepts are studied.

Definition 2.1. The fibrewise fuzzy topology (written as FWFTS) on a FW set m over FTS (b, $\Lambda$ ) signifies any fuzzy topology on $\mathrm{m}$ for which the proj. $\mathrm{P}$ is a fuzzy continuous.

For example, we can assume that $(b, \Lambda)$ like a FWFTS over itself by the identity as proj.. Also, the fuzzy topological product (see [5]) $\mathrm{b} \times \mathrm{t}$, for every FTS $\mathrm{t}$, can be regarded like a FWFTS's over $b$, by the first proj. and in the same way for every fuzzy subspace (see [4]) of $b \times t$.

\section{Remark 2.2.}

(a) In FWFTS, we carry out over FTS $(b, \Lambda)$ as a base space. If $b$ is a point-space, the theory changes to that of ordinary fuzzy topology.

(b) A FWFTS's over b is just a FTS $(\mathrm{m}, \tau)$ with a fuzzy continuous proj. mapping P : $(\mathrm{m}, \tau) \rightarrow$ $(\mathrm{b}, \Lambda)$.

(c) The coarsest fuzzy topology got by $P$, in which the fuzzy open sets of $(m, \tau)$ are the exactly the pre image of the fuzzy open set of $(b, \Lambda)$. 
(d) The FWFTS over (b, $\Lambda$ ) is defined to be a FW set over b with FWFTS.

(e) We consider the fuzzy topological product (written as FTP) b $\times$ t, for every FTS t, like a FWFTS's over b by the first proj..

Definition 2.3. The FW-M $\theta: \mathrm{m} \rightarrow \mathrm{N}$ where $(\mathrm{m}, \tau)$ and $(\mathrm{N}, \sigma)$ are FWFTS's over $(\mathrm{b}, \Lambda)$ is said to be:

(a) Fuzzy continuous if $b \in b$ and for every point $m \in m_{b}$, the pre image of every fuzzy open set of $\theta(\mathrm{m})$ is a fuzzy open set of $\mathrm{m}$.

(b) Fuzzy open if $b \in b$ and for every point $m \in m_{b}$, the image of every fuzzy open set of $m$ is a fuzzy open set of $\theta(\mathrm{m})$.

(c) Fuzzy closed if $b \in b$ and for every point $m \in m_{b}$, the image of every fuzzy closed set of $m$ is a fuzzy closed set of $\theta(\mathrm{m})$.

If $\theta: m \rightarrow N$ is a FW-M where $\mathrm{m}$ is a FW set and $(\mathrm{N}, \sigma)$ is a FWFTS over $(\mathrm{b}, \Lambda)$. We can give $\mathrm{m}$ the induced fuzzy topology (see [4]), in the ordinary sense and this is necessarily a FWFtopology. We may refer to it, therefore, like the induced FWF-topology and note the next characterizations.

Theorem 2.4. Let $\theta: \mathrm{m} \rightarrow \mathrm{N}$ be a FW-M, where $(\mathrm{N}, \sigma)$ a FWFTS over $(\mathrm{b}, \Lambda)$ and $\mathrm{m}$ has the induced FWF-topology. Then, for every FWFTS $(0, \delta)$ a FW-M $\varphi: 0 \rightarrow(\mathrm{m}, \tau)$ is a fuzzy continuous iff the composition $\theta \circ \varphi: o \rightarrow \mathrm{N}$ is a fuzzy continuous.

Proof. $(\Rightarrow)$ Suppose that $\varphi$ is a fuzzy continuous. Let $\mathrm{q} \in \mathrm{Ob} ; \mathrm{b} \in \mathrm{b}$ and let $\mathrm{V}$ be fuzzy open set of $(\theta \circ \varphi)(q)=n \in N_{b}$ in $N$. Since $\theta$ is a fuzzy continuous, then $\theta^{-1}(V)$ is a fuzzy open set containing $\varphi(q)=m \in m_{b}$ in $m$. Since $\varphi$ is a fuzzy continuous, then $\varphi^{-1}\left(\theta^{-1}(V)\right)$ is a fuzzy open set containing $\mathrm{q} \in \mathrm{o}_{\mathrm{b}}$ in $\mathrm{o}$ and $\varphi^{-1}\left(\theta^{-1}(\mathrm{~V})\right)=(\theta \circ \varphi)^{-1}(\mathrm{~V})$ is a fuzzy open set containing $\mathrm{q} \in \mathrm{o}_{\mathrm{b}}$ in o.

$(\Leftarrow)$ Suppose that $\theta$ o $\varphi$ is a fuzzy continuous. Let $\mathrm{q} \in \mathrm{ob} ; \mathrm{b} \in \mathrm{b}$ and $\mathrm{U}$ be a fuzzy open set of $\varphi(q)=m \in m_{b}$ in $m$. Since $\theta$ is a fuzzy open then, $\theta(\mathrm{U})$ is a fuzzy open set containing $\theta(\mathrm{m})=$ $\theta(\varphi(q))=n \in N_{b}$ in $N$. Since $\theta \circ \varphi$ is a fuzzy continuous, then $(\theta \circ \varphi)^{-1}(\theta(U))=\varphi^{-1}(U)$ is a fuzzy open set containing $\mathrm{q} \in \mathrm{O}_{\mathrm{b}}$ in $\mathrm{o}$.

Theorem 2.5. Let $\theta: \mathrm{m} \rightarrow \mathrm{N}$ be a FW-M where, $(\mathrm{N}, \sigma)$ a FWFTS over $(b, \Lambda)$ and $\mathrm{m}$ has the induced FWF-topology. If for every FWFTS $(o, \delta)$ a subjective FW-M $\varphi: 0 \rightarrow(\mathrm{m}, \tau)$ is a fuzzy open iff the composition $\theta \circ \varphi: o \rightarrow \mathrm{N}$ is a fuzzy open.

Proof. $(\Rightarrow)$ Suppose that $\varphi$ is a fuzzy open. Let $q \in \mathrm{ob}_{\mathrm{b}} ; \mathrm{b} \in \mathrm{b}$ and let $\mathrm{U}$ be fuzzy open set of $\mathrm{q}$ in o. Since $\varphi$ is a fuzzy open, $\varphi(U)$ is a fuzzy open set containing $\varphi(q)=m \in m_{b}$ in $m$. Since $\theta$ is a fuzzy open, then $\theta(\varphi(\mathrm{U}))$ is a fuzzy open set containing $\theta(\mathrm{m})=\theta(\varphi(q))=(\theta \circ \varphi)(q)=\mathrm{n} \in \mathrm{N}_{\mathrm{b}}$ in $\mathrm{N}$ and $\theta(\varphi(\mathrm{U}))=(\theta \circ \varphi)(\mathrm{U})$.

$(\Leftarrow)$ Suppose that $\theta \circ \varphi$ is a fuzzy open. Let $\mathrm{q} \in \mathrm{ob} ; \mathrm{b} \in \mathrm{b}$ and $\mathrm{U}$ be a fuzzy open set of $\mathrm{q} \in \mathrm{Q}_{\mathrm{b}}$ in Q. Since $\theta \circ \varphi$ is a fuzzy open then, $(\theta \circ \varphi)(U)$ is a fuzzy open set containing $\theta \circ \varphi(q))=n \in$ $\mathrm{N}_{\mathrm{b}}$ in $\mathrm{N}$. Since $\mathrm{m}$ has the induced FWF-topology then $\left.\theta^{-1}(\theta \circ \varphi)(\mathrm{U})\right)=\varphi(\mathrm{U})$ is a fuzzy open containing $\left.\theta^{-1}(\theta \circ \varphi)(q)\right)=\varphi(q)=m \in M_{b}$ in $M$. 
Let us pass the general cases of Theorems (2.4) and (2.5) as follows: Similarly in case of families $\left\{\theta_{r}\right\}$ of FW-M's, where $\theta_{r}: \mathrm{m} \rightarrow \mathrm{N}_{r}$ with $\left(\mathrm{N}_{r}, \sigma_{r}\right)$ FWFTS over b for every r. Specially, given a family $\left\{\left(\mathrm{m}_{r}, \tau_{r}\right)\right\}$ of FWFTS over $\mathrm{b}$, the FWF-topological product $\prod_{\mathrm{b}}$ $\mathrm{m}_{\mathrm{r}}$ is defined to be the FW-product with the FWF-topology generated by the family of proj's $\pi_{r}$ : $\prod_{\mathrm{b}} \mathrm{m}_{\mathrm{r}} \rightarrow \mathrm{m}_{r}$. Then for every FWFTS $(\mathrm{o}, \delta)$ over $\mathrm{b}$ a FW-M $\xi: \mathrm{o} \rightarrow \prod_{\mathrm{b}} \mathrm{m}_{\mathrm{r}}$ is a fuzzy continuous (resp. fuzzy open). For example when $\mathrm{m}_{r}=\mathrm{m}$ for every index $r$ we see that the diagonal $\Delta: \mathrm{m} \rightarrow$ $\prod_{\mathrm{b}} \mathrm{m}$ is a fuzzy continuous (resp. fuzzy open) iff the composition $\pi_{r} \mathrm{o} \Delta=i d_{\mathrm{m}}$ is a fuzzy continuous (resp. fuzzy open).

Again if $\left\{\left(\mathrm{m}_{r}, \tau_{r}\right)\right\}$ is a family of FWFTS's over $\mathrm{b}$ and $\varphi: \bigsqcup_{\mathrm{b}} \mathrm{m}_{\mathrm{r}} \rightarrow \mathrm{m}$ is a FW-M where $(\mathrm{m}, \tau)$ a FWF-topology over $\mathrm{b}$ and $\bigsqcup_{\mathrm{b}} \mathrm{m}_{\mathrm{r}}$ is a FWF-topological coproduct at the set-theoretic level with the ordinary coproduct fuzzy topology, also for every FWF-topology $\left(\mathrm{m}_{r}, \tau_{r}\right)$ with the family of FW insertions $\sigma_{r}: \mathrm{m}_{\mathrm{r}} \rightarrow \bigsqcup_{\mathrm{b}} \mathrm{m}_{\mathrm{r}}$ is a fuzzy continuous (resp. fuzzy open) iff the composition $\varphi_{r}=\varphi$ o $\sigma_{r}: \mathrm{m}_{r} \rightarrow \mathrm{m}$ is a fuzzy continuous (resp. fuzzy open). For example when $\mathrm{m}_{r}=\mathrm{m}$ for every index $r$ we see that the codiagonal $\nabla: \bigsqcup_{\mathrm{b}} \mathrm{m}_{r} \rightarrow \mathrm{m}$ is a fuzzy continuous (resp. fuzzy open).

\section{Fibrewise closed and fibrewise open fuzzy topological spaces}

We present the ideas of fibrewise closed and fibrewise open FTS's fuzzy topological spaces over b, several property on the obtained concepts are studies.

Definition 3.1. The FWFTS $(m, \tau)$ over $(b, \Lambda)$ is said to be fibrewise closed (written as FWCFTS) if the proj. $\mathbf{P}$ is a fuzzy closed.

For example, trivial FWFTS with fuzzy compact fibre (see [4]) is a FWCFTS.

Theorem 3.2. Let $\theta: \mathrm{m} \rightarrow \mathrm{N}$ be fuzzy closed FW-M where (m, $\tau)$ and $(\mathrm{N}, \sigma)$ are FWCFTS's over $(\mathrm{b}, \Lambda)$. Then $\mathrm{m}$ is a FWCFTS if $\mathrm{N}$ is a FWCFTS.

Proof. Assume that $\theta: \mathrm{m} \rightarrow \mathrm{N}$ is a closed FW-M and $\mathrm{N}$ is a FWCFTS i.e. the proj. $\mathrm{P}_{\mathrm{n}}: \mathrm{N} \rightarrow \mathrm{b}$ is a fuzzy closed. To prove that $\mathrm{m}$ is a FWCFTS i.e. the proj. $\mathrm{P}_{\mathrm{m}}: \mathrm{m} \rightarrow \mathrm{b}$ is a fuzzy closed. Now, let $\mathrm{m} \in \mathrm{m}_{\mathrm{b}} ; \mathrm{b} \in \mathrm{b}$, and let $\mathrm{F}$ be a fuzzy closed set of $\mathrm{m}$. Since $\theta$ is a fuzzy closed so that $\theta(\mathrm{F})$ is a fuzzy closed set of $\theta(m)=n \in N_{b}$ in $N$. Since $P_{N}$ is a fuzzy closed so $P_{N}(\theta(F))$ a fuzzy closed set in $\mathrm{b}$. But, $\mathrm{P}_{\mathrm{N}}(\theta(\mathrm{F}))=\mathrm{P}_{\mathrm{N}}$ o $\theta(\mathrm{F})=\mathrm{P}_{\mathrm{m}}(\mathrm{F})$ is a fuzzy closed set of $\mathrm{b}$. Thus, $\mathrm{P}_{\mathrm{m}}$ is a fuzzy closed and $m$ is a FWCFTS.

Theorem 3.3. If $(\mathrm{m}, \tau)$ is a FWFTS over $(\mathrm{b}, \Lambda)$. Assume that $\mathrm{m}_{j}$ is a FWCFTS for every member $\mathrm{m}_{j}$ of a finite covering of $\mathrm{m}$. Then $\mathrm{m}$ is a FWCFTS.

Proof. Assume that $\mathrm{m}$ is a FWFTS over $\mathrm{b}$, then the proj. $\mathrm{P}_{\mathrm{m}}: \mathrm{m} \rightarrow \mathrm{b}$ exist. To prove that $\mathrm{P}$ is a fuzzy closed. Since $\mathrm{m}_{j}$ is a FWCFTS, then the proj. $\mathrm{P}_{\mathrm{mj}}: \mathrm{m}_{\mathrm{j}} \rightarrow \mathrm{b}$ is a fuzzy closed for every member $\mathrm{m}_{j}$ of a finite covering of $\mathrm{m}$. Let $\mathrm{F} \subseteq \mathrm{m}$ be a fuzzy closed set. Then $\mathrm{P}(\mathrm{F})=U \mathrm{P}_{j}\left(\mathrm{~m}_{j} \cap \mathrm{F}\right)$ which is a finite union of fuzzy closed sets and so $\mathrm{P}$ is a fuzzy closed, so that $\mathrm{m}$ is a FWCFTS.

Theorem 3.4. Let $(m, \tau)$ be a FWFTS over $(b, \Lambda)$. Then, $(m, \tau)$ is a FWCFTS iff for every fibre $\mathrm{m}_{\mathrm{b}}$ of $\mathrm{m}$ and every fuzzy open set $\mathrm{U}$ of $\mathrm{m}_{\mathrm{b}} \subseteq \mathrm{m}$, there is a fuzzy open set $\mathrm{O}$ of $\mathrm{b}$ where $\mathrm{mo} \subseteq \mathrm{U}$. 
Proof. $(\Rightarrow)$ Assume that $\mathrm{m}$ is a FEFTS i.e. the proj. $\mathrm{P}: \mathrm{m} \rightarrow \mathrm{b}$ is a fuzzy closed. Now, let $\mathrm{b} \in \mathrm{b}$ and $U$ be fuzzy open set of $m_{b}$, so we have $m-U$ is a fuzzy closed set and $P(m-U)$ is a fuzzy closed set. Let $\mathrm{O}=\mathrm{b}-\mathrm{P}(\mathrm{m}-\mathrm{U})$ is a fuzzy open set of $\mathrm{b}$. Hence, $\mathrm{m}_{\mathrm{O}}=\mathrm{P}^{-1}(\mathrm{~b}-\mathrm{P}(\mathrm{m}-\mathrm{U}))$ which is a subset of $\mathrm{U}$. Thus $\mathrm{m}_{\mathrm{O}} \subseteq \mathrm{U}$.

$(\Leftarrow)$ Suppose that the assumption is hold, to show that $\mathrm{m}$ is a FWCFTS. Let $\mathrm{F}$ be fuzzy closed set in $\mathrm{m}$. Let $\mathrm{b} \in \mathrm{b}-\mathrm{P}(\mathrm{F})$ and every fuzzy open set $\mathrm{U}$ of $\mathrm{m}_{\mathrm{b}} \subseteq \mathrm{m}$. By assumption there is a fuzzy open set $\mathrm{O}$ of $\mathrm{b}$ such that $\mathrm{m}_{\mathrm{O}} \subseteq \mathrm{U}$. It's easy to show that $\mathrm{O} \subseteq \mathrm{b}-\mathrm{P}(\mathrm{F})$. So that $\mathrm{b}-\mathrm{P}(\mathrm{F})$ is $\mathrm{a}$ fuzzy open set in b. Hence $\mathrm{P}(\mathrm{F})$ is a fuzzy closed in $\mathrm{b}, \mathrm{P}$ is a fuzzy closed and $\mathrm{m}$ is a FWCFTS.

Definition 3.5. The FWFTS $(m, \tau)$ over $(b, \Lambda)$ is said to be fibrewise open (written as FWOFTS) if the proj. $\mathrm{P}$ is a fuzzy open.

For example, trivial FWFTS's are always FWOFTS.

Theorem 3.6. Let $\theta: m \rightarrow N$ be a fuzzy open FW-M where $(m, \tau),(N, \sigma)$ are FWFTS over $(b$, $\Lambda$ ). If $\mathrm{N}$ is a FWOFTS, then $\mathrm{m}$ is a FWOFTS.

Proof. Since $\mathrm{N}$ is a FWOFTS, we have $\mathrm{P}_{\mathrm{n}}: \mathrm{N} \rightarrow \mathrm{b}$ is a fuzzy open. To prove that $\mathrm{P}_{\mathrm{m}}$ is a fuzzy open, i.e. the proj. $\mathrm{P}_{\mathrm{m}}: \mathrm{m} \rightarrow \mathrm{b}$ is a fuzzy open. Let $\mathrm{m} \in \mathrm{m}_{\mathrm{b}} ; \mathrm{b} \in \mathrm{b}$, and let $\mathrm{U}$ be a fuzzy open set of $\mathrm{m}, \theta(\mathrm{U})$ is a fuzzy open set of $\theta(\mathrm{m})=\mathrm{n} \in \mathrm{N}_{\mathrm{b}} \subseteq \mathrm{N}$ since $\theta$ is a fuzzy open. Also, since $\mathrm{N}$ is a FWOFTS, then the proj. $\mathrm{P}_{\mathrm{n}}: \mathrm{N} \rightarrow \mathrm{b}$ is a fuzzy open and $\mathrm{P}_{\mathrm{N}}(\theta(\mathrm{U}))$ is a fuzzy open set in $\mathrm{b}$, but $\mathbf{P}_{\mathrm{n}}(\theta(U))=\mathbf{P}_{\mathrm{n}}$ o $\theta(U)=\mathbf{P}_{m}(U)$. So that $\mathbf{P}_{\mathrm{m}}$ is a fuzzy open and $\mathrm{m}$ is a FWOFTS.

Theorem 3.7. Let $\theta: \mathrm{m} \rightarrow \mathrm{N}$ be a FW-M, where $(\mathrm{m}, \tau),(\mathrm{N}, \sigma)$ are FWFTS's over $(b, \Lambda)$. Assume that the product:

$$
i d_{\mathrm{m}} \times \theta:(\mathrm{m} \times \mathrm{b}, \tau \times \tau) \rightarrow(\mathrm{m} \times \mathrm{b}, \tau \times \sigma)
$$

is a fuzzy open and $m$ is a FWOFTS. Then $\theta$ itself fuzzy open.

Proof. Consider the following figure:

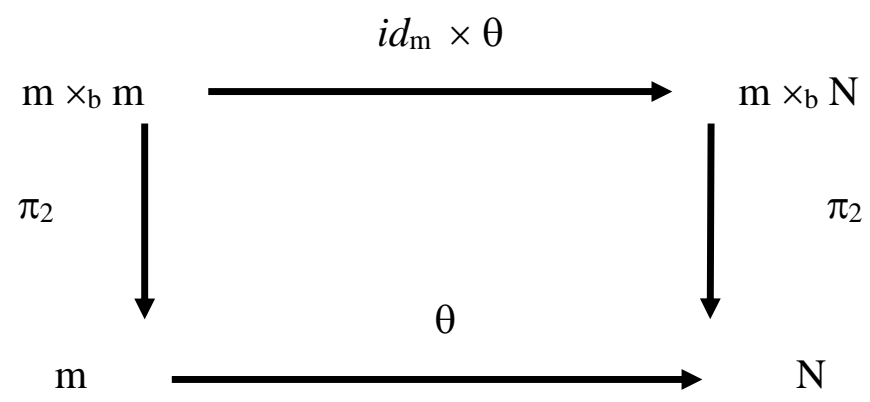

Figure 1. Diagraph of Theorem 3.7.

The projection on the right is surjective. While the projection on the left is a fuzzy open since $\mathrm{m}$ is a FWOFTS. Thus $\pi_{2} \mathrm{o} i d_{\mathrm{m}} \times \theta=\theta$ o $\pi_{2}$ is a fuzzy open and so $\theta$ is a fuzzy open.

Our next three results apply equally to FWCFTS's and FWOFTS's.

Theorem 3.8. Let $\theta: m \rightarrow N$ be a surjection FW fuzzy continuous where $(m, \tau),(N, \sigma)$ are FWFTS's over $(b, \Lambda)$. Then $\mathrm{N}$ is a FWCFTS (resp. FWOFTS) if $\mathrm{m}$ is a FWCFTS (resp. FWOFTS). 
Proof. Suppose that $m$ is a FWCFYS (resp. FWOFTS). Then the proj. $\mathrm{P}_{\mathrm{m}}: \mathrm{m} \rightarrow \mathrm{b}$ is a fuzzy closed (resp. fuzzy open). To prove that $\mathrm{N}$ is a FWCFTS (resp. FWOFTS) over b i.e. the proj. $\mathrm{P}_{\mathrm{n}}$ $:(\mathrm{N}, \sigma) \rightarrow(\mathrm{b}, \Lambda)$ is a fuzzy closed (resp. fuzzy open). Suppose that $\mathrm{n} \in \mathrm{N}_{\mathrm{b}} ; \mathrm{b} \in \mathrm{b}$. Let $\mathrm{V}$ be fuzzy closed (resp. fuzzy open) set of $n$. Since $\theta$ is a fuzzy continuous so $\theta^{-1}(V)$ is a fuzzy closed (resp. fuzzy open) set of $\theta^{-1}(n)=m \in m_{b} \subseteq m$. Since $P_{m}$ is a fuzzy closed (resp. fuzzy open), then $\mathrm{P}_{\mathrm{m}}\left(\theta^{-1}(\mathrm{~V})\right)$ is a fuzzy closed (resp. fuzzy open) in $\mathrm{b}$, but $\mathrm{P}_{\mathrm{m}}\left(\theta^{-1}(\mathrm{~V})\right)=\mathrm{P}_{\mathrm{m}} \mathrm{O} \theta^{-1}(\mathrm{~V})=\mathrm{P}_{\mathrm{n}}(\mathrm{V})$. Thus $\mathbf{P}_{\mathrm{n}}$ is a fuzzy closed (resp. fuzzy open), and $\mathrm{N}$ is a FWCFTS (resp. FWOFTS).

Theorem 3.9. If $(m, \tau)$ is a FWFTS over $(b, \Lambda)$. Assume that $m$ is a FWCFTS (resp. FWOFTS) over $b$, then $m_{b} *$ is a FWCFTS (resp. FWOFTS) over $b^{*}$ for every fuzzy subspace $b^{*} \subseteq b$.

Proof. Assume that $\mathrm{m}$ is a FWCFTS (resp. FWOFTS), so that the proj. P : $\mathrm{m} \rightarrow \mathrm{b}$ is a fuzzy closed (resp. fuzzy open). To prove that $\mathrm{m}_{\mathrm{b}}$ is a fuzzy closed (resp. fuzzy open), i.e. the proj. $\mathrm{P}_{\mathrm{b}^{*}}$ $: \mathrm{m}_{\mathrm{b}^{*}} \rightarrow \mathrm{b}^{*}$ is a fuzzy closed (resp. fuzzy open). Let $\mathrm{m} \in \mathrm{m} \mid \mathrm{b}^{*}$, and $\mathrm{G}$ be fuzzy closed (resp. fuzzy open) set of $m$, we have $G \cap m_{b *}$ is a fuzzy closed (resp. fuzzy open) set of $m_{b^{*}} . P_{b} *(G \cap$ $\left.\mathrm{m}_{\mathrm{b}^{*}}\right)=\mathrm{P}\left(\mathrm{G} \cap \mathrm{m}_{\mathrm{b}^{*}}\right)=\mathrm{P}(\mathrm{G}) \cap \mathrm{P}\left(\mathrm{m}_{\mathrm{b}^{*}}\right)=\mathrm{P}(\mathrm{G}) \cap \mathrm{b}^{*}$ which is a fuzzy closed (resp. fuzzy open ) set in $b^{*}$. $\mathrm{P}_{\mathrm{b} *}$ is a fuzzy closed (resp. fuzzy open ). So that $\mathrm{m}_{\mathrm{b}}$ is a FWCFTS (resp. FWOFTS).

Theorem 3.10. Let $(m, \tau)$ be a FWFTS over $(b, \Lambda)$. Assume that $\left(m_{b j}, \tau\right)$ is a FWCFTS's (resp. FWOFTS's) over $\left(b_{j}, \Lambda_{b j}\right)$ for every member of a $\Lambda_{b j}$-fuzzy open covering of $b$. So $m$ is a FWCFTS (resp. FWOFTS) over b.

Proof. Assume that $\mathrm{m}$ is a FWFTS over b so, the proj. $\mathrm{P}: \mathrm{m} \rightarrow \mathrm{b}$ is exist .To prove that $\mathrm{P}$ is a fuzzy closed (resp. fuzzy open). Since $m_{b}$ is a FWCFTS (resp. FWOFTS) over $b_{j}$ for every member of a $\Lambda_{b j}$ fuzzy open covering of $b$, then the proj. $\mathbf{P}_{\mathrm{mj}}$ : $\mathrm{m}_{\mathrm{bj}} \rightarrow \mathrm{b}_{\mathrm{j}}$ is a fuzzy closed (resp. fuzzy open). Now, let $F$ be fuzzy closed (resp. fuzzy open) set of $m_{b} ; b \in b, P(F)=U P_{b j}(F \cap$ $\mathrm{m}_{\mathrm{bj}}$ ) which is a finite union of fuzzy closed (resp. fuzzy open) sets of $\mathrm{b}$. Thus $\mathbf{P}$ is a fuzzy closed (resp. fuzzy open) and $\mathrm{m}$ is a FWCFTS (resp. FWOFTS).

Actually, the past Theorem is true to locally finite closed covering and there are several subclasses of the class of FWOFTS's which induces many important examples and have interesting properties.

\section{Fibrewise locally sliceable and fibrewise locally sectionable fuzzy topological spaces}

We present the ideas of fibrewise locally sliceable and fibrewise locally sectionable fuzzy topological spaces over $(b, \Lambda)$, several properties on the obtained concepts are studied.

Definition 4.1. The FWFTS $(m, \tau)$ over $(b, \Lambda)$ is said to be locally sliceable (written as FW-LSLFTS) if for every point $\mathrm{m} \in \mathrm{m}_{\mathrm{b}} ; \mathrm{b} \in \mathrm{b}$, there is a fuzzy open set $\mathrm{w}$ of $\mathrm{b}$ and a section $s: \mathrm{w} \rightarrow$ $\mathrm{m}_{\mathrm{w}}$ and $s(\mathrm{~b})=\mathrm{m}$.

The condition leads to $\mathrm{P}$ is a fuzzy open for if $\mathrm{u}$ is a fuzzy open set of $\mathrm{m} \in \mathrm{m}$, then $s^{-1}\left(\mathrm{~m}_{\mathrm{w}} \cap \mathrm{u}\right)$ $\subseteq \mathrm{P}(\mathrm{u})$ is a fuzzy open set of $\mathrm{b} \in \mathrm{w}$, and hence in $\mathrm{b}$. The class of $\mathrm{b}$ FW-LSL-FTS is a finitely multiplicative stated in. 
Theorem 4.2. Let $\left\{\left(\mathrm{m}_{r}, \tau_{r}\right)\right\}_{r=1}^{k}$ be a finite family of FW-LSL-FTS's over $(\mathrm{b}, \Lambda)$. Then the FWFtopological product $\left(\mathrm{m}=\prod_{\mathrm{b}} \mathrm{m}_{\mathrm{r}}, \tau\right)$ is a FW-LSL-FTS.

Proof. Let $\mathrm{m}=\left(\mathrm{m}_{r}\right)$ be a point of $\mathrm{m}_{\mathrm{b}} ; \mathrm{b} \in \mathrm{b}$, so that $\mathrm{m}_{r}=\pi_{r}(\mathrm{~m})$ for every index $r$. Since $\mathrm{m}_{r}$ is a FW-LSL-FTS, there is a fuzzy open set $\mathrm{w}_{r}$ of $\mathrm{b}$ and a section $\mathrm{s}_{r}: \mathrm{w}_{r} \rightarrow \mathrm{m}_{r} \mid \mathrm{w}_{r}$, where $s_{r}(\mathrm{~b})=\mathrm{m}_{r}$. Then, the intersection $\mathrm{w}=\mathrm{w}_{1} \cap \ldots \cap \mathrm{w}_{n}$ is a fuzzy open set of $\mathrm{b}$ and a section $s: \mathrm{w} \rightarrow \mathrm{m}_{\mathrm{w}}$ is given by $\left(\pi_{\mathrm{r}} \mathrm{O} s\right)(\mathrm{w})=s_{r}(\mathrm{w})$ for every index $r$ and every point $\mathrm{w} \in \mathrm{W}$.

Theorem 4.3. Let $\theta: m \rightarrow n$ fuzzy continuous, surjection FW-M, where $(m, \tau)$ and $(n, \sigma)$ are FWFTS's over $(\mathrm{b}, \Lambda)$. If $\mathrm{m}$ is a FW-LSL-TTS, then $\mathrm{n}$ is so.

Proof. Let $\mathrm{n} \in \mathrm{N}_{\mathrm{b}} ; \mathrm{b} \in \mathrm{b}$. Then $\mathrm{n}=\theta(\mathrm{m})$, for some $\mathrm{m} \in \mathrm{m}_{\mathrm{b}}$. If $\mathrm{m}$ is a FW-LSL-FTS, then there is a fuzzy open set $\mathrm{w}$ of $\mathrm{b}$ and a section $s: \mathrm{w} \rightarrow \mathrm{m}_{\mathrm{w}}$ where $s(\mathrm{~b})=\mathrm{m}$. Then $\theta$ o $s: \mathrm{w} \rightarrow \mathrm{n}_{\mathrm{w}}$ is a section such that $s(\mathrm{~b})=\mathrm{n}$ as required.

Definition 4.4. The FWFTS $(m, \tau)$ over $(b, \Lambda)$ is said to be fibrewise discrete (written as FW-DFTS) if the proj. $\mathrm{P}$ is a local fuzzy homeomorphism (i.e. fuzzy continuous, fuzzy open, one to one, onto).

This means, we recall, that for every point $\mathrm{b} \in \mathrm{b}$ and every point $\mathrm{m} \in \mathrm{m}_{\mathrm{b}} ; \mathrm{b} \in \mathrm{b}$ there is $\mathrm{a}$ fuzzy open set $\mathrm{v}$ of $\mathrm{m}$ in $\mathrm{m}$ and a fuzzy open set $\mathrm{w}$ of $\mathrm{b}$ in $\mathrm{b}$ where $\mathrm{P}$ maps $\mathrm{v}$ fuzzy homeomorphically onto $\mathrm{w}$, in that case we say that $\mathrm{w}$ is evenly covered by $\mathrm{v}$. It is clear that FWD-FTS's are FW-LSL-FTS there for FWOFTS.

The class of FW-D-FTS's is a finitely multiplicative.

Theorem 4.5. Let $\left\{\left(\mathrm{m}_{r}, \tau_{r}\right)\right\}_{r=1}^{k}$ be a finite family of FW-D-FTS over $(\mathrm{b}, \Lambda)$. Then the FWFTproduct $\left(\mathrm{m}=\prod_{\mathrm{b}} \mathrm{m}_{\mathrm{r}}, \tau\right)$ is a FW-D-FTS.

Proof. Given a point $\mathrm{m} \in \mathrm{m}_{\mathrm{b}} ; \mathrm{b} \in \mathrm{b}$, there is for every index $r$ an open set $\mathrm{u}_{r}$ of $\pi_{r}(\mathrm{~m})$ in $\mathrm{m}_{r}$, where the proj. $\mathbf{P}_{r}=\mathrm{P}$ o $\pi_{r}^{-1}$ maps $\mathrm{u}_{r}$ fuzzy homeomorphically onto the fuzzy open $\mathrm{P}_{r}\left(\mathrm{u}_{r}\right)=\mathrm{w}_{r}$ of b. Then the fuzzy open $\prod_{b} U_{r}$ of $m$ is mapped fuzzy homeomorphically onto the intersection $\mathrm{w}=$ $\bigcap \mathrm{w}_{r}$ which is a fuzzy open of $\mathrm{b}$.

An attractive characterization of FW-D-FTS's is given by the following:

Theorem 4.6. If $(m, \tau)$ is a FWFTS over $(b, \Lambda)$. Then, $m$ is a FW-D-FTS iff

(a) $m$ is a FWOFTS

(b) The diagonal embedding $\Delta: \mathrm{m} \rightarrow \mathrm{m} \times \mathrm{b}$ m is a fuzzy open

Proof. $(\Leftarrow)$ Suppose that (a) and (b) are satisfied. Let $\mathrm{m} \in \mathrm{m}_{\mathrm{b}} ; \mathrm{b} \in \mathrm{b}$, then $\Delta(\mathrm{m})=(\mathrm{m}, \mathrm{m})$ admits a fuzzy open set in $m x_{b} m$ which is entirely contained in $\Delta(\mathrm{m})$. Without real lacking in general, we may suppose the fuzzy open set is of the form $u \times_{b} u$, where $u$ is a fuzzy open set of $m$ in $m$. Then $\mathrm{P} \mid \mathrm{u}$ is a fuzzy homeomorphism. Therefore, $\mathrm{m}$ is a FW-D-FTS.

$(\Rightarrow)$ Assume that $\mathrm{m}$ is a FW-D-FTS. We have already seen that $\mathrm{m}$ is a FWOFTS. To prove that $\Delta$ is a fuzzy open, it is sufficient to prove that $\Delta(\mathrm{m})$ is a fuzzy open in $\mathrm{m} \times_{\mathrm{b}} \mathrm{m}$. So let $\mathrm{m} \in \mathrm{m}_{\mathrm{b}} ; \mathrm{b} \in$ $\mathrm{b}$, and let $\mathrm{u}$ be a fuzzy open set of $\mathrm{m}$ in $\mathrm{m}$, where $\mathrm{w}=\mathrm{P}(\mathrm{u})$ is a fuzzy open set of $\mathrm{b}$ in $\mathrm{b}$ and $\mathrm{P}$ 
maps $\mathrm{u}$ fuzzy homeomorphically onto $\mathrm{w}$. Then $\mathrm{u} \mathrm{x}_{\mathrm{b}} \mathrm{u}$ is contained in $\Delta(\mathrm{m})$ since if not then there exist distinct $\lambda, \lambda^{*} \in \mathrm{m}_{\mathrm{w}}$, where $\mathrm{w} \in \mathrm{w}$ and $\lambda, \lambda^{*} \in \mathrm{u}$, which is absurd.

Fuzzy open subset of FW-D-FTS's is also FW-D-FTS, Actually, we have.

Theorem 4.7. Let $\theta: m \rightarrow n$ be a fuzzy continuous, injection FW-M, where $(m, \tau)$ and $(n, \sigma)$ are FWOFTS's over $(b, \Lambda)$. If $n$ is a FW-D-FTS, then $m$ is so.

Proof. Consider the diagram shown below.

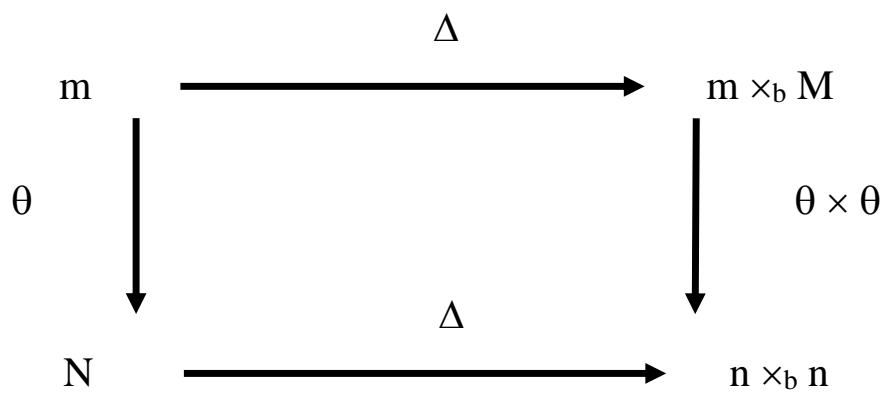

Figure 2. Diagraph of Theorem 4.7 .

Since $\theta$ is a fuzzy continuous so is $\theta \times \theta$. Now $\Delta(n)$ is open in $n \times_{b} n$, by Theorem (4.6). Since $\mathrm{n}$ is a FW-D-FTS, then $\Delta(\mathrm{m})=\Delta\left(\left(\theta^{-1}(\mathrm{n})\right)\right)=(\theta \times \theta)^{-1}(\Delta(\mathrm{n}))$ is a fuzzy open in $\mathrm{m} \times \mathrm{b}$. Thus, Theorem (4.7) follows from Theorem (4.6).

Theorem 4.8. Assume that $\theta: \mathrm{m} \rightarrow \mathrm{n}$ is a fuzzy open, surjection $\mathrm{FW}-\mathrm{M}$, where $(\mathrm{m}, \tau)$ and $(\mathrm{n}, \sigma)$ are FWOFTS's over $(\mathrm{b}, \Lambda)$. If $\mathrm{m}$ is a FW-D-FTS, then $\mathrm{n}$ is so.

Proof. In the above figure, with these fresh hypotheses on $\theta$, if $\mathrm{m}$ is a FW-D-FTS, then $\Delta(\mathrm{m})$ is a fuzzy open in $\mathrm{m} \times_{\mathrm{b}} \mathrm{m}$, by Theorem (4.6), so $\Delta(\mathrm{n})=\Delta((\theta(\mathrm{m})))=(\theta \times \theta)(\Delta(\mathrm{m}))$ is a fuzzy open in $\mathrm{n} \times \times_{\mathrm{b}} \mathrm{n}$. Thus, Theorem (4.8) follows from Theorem (4.6) again.

Theorem 4.9. If $\theta, \varphi: m \rightarrow n$ is a fuzzy continuous FW-M, where $(m, \tau)$ is a FWFTS and $(n, \sigma)$ is a FW-D-FTS over $(\mathrm{b}, \Lambda)$. Then the coincidence set $K(\theta, \varphi)$ of $\theta$ and $\varphi$ is a fuzzy open in $\mathrm{m}$.

Proof. The coincidence set is precisely $\Delta^{-1}(\theta \times \varphi)^{-1}(\Delta(N))$, where:

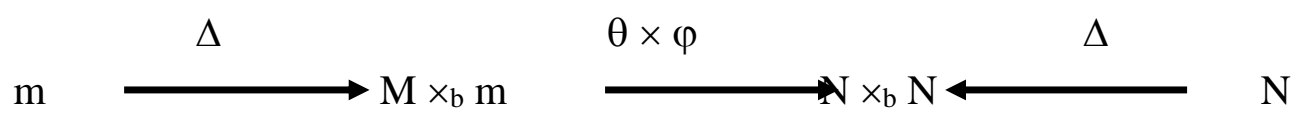

Figure 3. Diagraph of Theorem 4.9.Fig. 4.2.

Hence Theorem (4.9) follows at once from Theorem (4.6). In particular, take $\mathrm{m}=\mathrm{n}$, take $\theta=i d_{m}$ and take $\varphi=s$ o $\rho$ where $s$ is a section, we conclude that $s$ is a fuzzy open embedding when $\mathrm{m}$ is a FW-D-FTS.

Theorem 4.10. If $\theta: m \rightarrow n$ is a fuzzy continuous FW-M, where $(m, \tau)$ is a FWOFTS and $(n, \sigma)$ is a FW-D-FTS over $(\mathrm{b}, \Lambda)$. Then the FW-graph: $\Gamma: \mathrm{m} \rightarrow \mathrm{m} \times_{b} \mathrm{n}$ of $\theta$ is a fuzzy open embedding. 
Proof. The FW-graph is defined in the same way as the ordinary graph, but with values in the FWFT-product, therefore the diagram shown below is commutative.

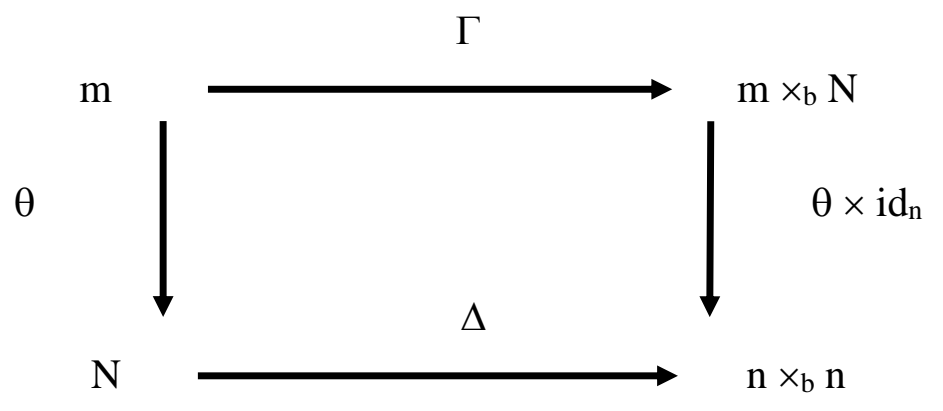

Figure 4. Diagraph of Theorem 4.10.

Since $\Delta(\mathrm{n})$ is a fuzzy open in $\mathrm{n} \times_{b} \mathrm{n}$, by Theorem (4.6), so $\Gamma(\mathrm{m})=\left(\theta \times i d_{n}\right)^{-1}(\Delta(\mathrm{n}))$ is a fuzzy open in $\mathrm{m} \times_{b} \mathrm{n}$ as asserted.

Remark 4.11. If $(m, \tau)$ is a FW-D-FTS over $(b, \Lambda)$ then for every point $m \in m_{b} ; b \in b$, there is a fuzzy open set $\mathrm{w}$ of $\mathrm{b}$ a unique section $s: \mathrm{w} \rightarrow \mathrm{m}_{w}$ exist satisfying $s(\mathrm{~b})=\mathrm{m}$, we may refer to $\mathrm{s}$ as the section through $\mathrm{m}$.

Definition 4.12. The FWFTS $(m, \tau)$ over $(b, \Lambda)$ is said to be locally sectionable (written as FWLSE-FTS) if for every point $\mathrm{b} \in \mathrm{b}$, it admits a fuzzy open set $\mathrm{w}$ and a section $s: \mathrm{w} \rightarrow \mathrm{m}_{w}$.

Remark 4.13. The non-empty FW-LSL-FTS's are FW-LSE-FTS's, but the converse is false. In fact, FW-LSE-FTS's are not necessarily FWOFYS, for example take $m=(-1,1] \subseteq \mathbb{R}$ with (m, $\tau)$, the natural projection onto $b=\mathbb{R} \mid \mathbb{Z} ;(b, \Lambda)$.

The class of FW-LSE-FTS's is a finitely multiplicative.

Theorem 4.14. If $\left\{\left(\mathrm{m}_{r}, \tau_{r}\right)\right\}_{r=1}^{k}$ is a finite family of FW-LSE-FTS's over $(\mathrm{b}, \Lambda)$. Then the FWFT-product $\left(\mathrm{m}=\prod_{\mathrm{b}} \mathrm{m}_{\mathrm{r}}, \tau\right)$ is a FW-LSE-FTS.

Proof. Given a point $\mathrm{b}$ of $\mathrm{b}$, there exist a fuzzy open set $\mathrm{w}_{r}$ of $\mathrm{b}$ and a section $\mathrm{s}_{r}: \mathrm{w}_{r} \rightarrow \mathrm{m}_{r} \mid \mathrm{w}_{r}$ for every index $r$. Since there are finite numbers of indices the intersection $\mathrm{w}$ of the fuzzy open sets $\mathrm{w}_{r}$ is also a fuzzy open set of $\mathrm{b}$, and a section $\mathrm{s}: \mathrm{w} \rightarrow\left(\prod_{\mathrm{b}} \mathrm{m}_{\mathrm{r}}\right)_{\mathrm{w}}$ is given by $\left(\pi_{\mathrm{r}} \mathrm{O} s\right)(\mathrm{w})=$ $s_{r}(\mathrm{w})$, for $\mathrm{w} \in \mathrm{W}$.

Our last two result apply equally well to every of the above three Theorems.

Theorem 4.15. If $(m, \tau)$ is a FW-D-FTS over $(b, \Lambda)$. Suppose that $(m, \tau)$ is a FW-LSL-FTS, FWD-FTS or FW-LSE-FTS's over $(\mathrm{b}, \Lambda)$. Then so is $\mathrm{m}_{b^{*}}$ over $\mathrm{b}^{*}$ for every fuzzy open set $\mathrm{b}^{*} \subseteq \mathrm{b}$.

Theorem 4.16. Let $(m, \tau)$ be FWFTS over $(b, \Lambda)$. Assume that $m_{b j}$ is a FW-LSL-FTS, FW-DFTS or FW-LSE-FTS over $b_{j}$ for every member $b_{j}$ of a fuzzy open covering of $b$. So is $m$ over $b$. 


\section{Ibn Al-Haitham Jour. for Pure \& Appl. Sci. 34(3)2021}

Remark 4.17. It is not difficult to give examples of different FW-D-FTS's on the same FW-set which are equivalent, to FWFTS's. For this reason, we must be careful not to say the FW-DFTS.

\section{References}

1. Abo Khadra, A. A.; Mahmoud, S. S. ; Yousif Y. Y., Fibrewise near topological spaces, Journal of Computing, USA, 2012, 4, 5, May 223-230.

2.Chang, C. L.; Fuzz topological spaces. J. Math. Anal. Appl. 24 ,1968,182-190.

3. Englking, R., Outline of general topology, Amsterdam, 1989.

4. Ghanim, M. H.; Kerre E. E. ; Mashhour, A. S., Separation Axioms, Subspaces and Sums in Fuzzy Topology, Journal of Mathematical Analysis and Applications, Academic Press, Inc., 1984, 102 , 189-202.

5.Hutton, B., Products of Fuzzy Topological spaces, Topology and its Applications, NorthHolland Publishing Company, 1980, 11 ,59-67.

6. James, I. M., Fibrewise topology, Cambridge University Press, London 1989.

7. Mahmoud, S. S. ; Yousif, Y. Y., Fibrewise near separation axioms, International Mathematical Forum, Hikari Ltd, Bulgaria, 2012, 7,35 ,1725-1736.

8. Mohammed, N. F. ; Yousif ,Y. Y., Connected Fibrewise Topological Spaces, $2^{\text {nd. }}$ ISC-2019 College of Science, University of Al-Qadisiyah Scientific Conference, IOP Conf. Series: Journal of Physics: Conf. Series 1294 (2019) 032022 doi :10.1088/17426596/1294/1/032022, 24-25 April 2019, pp. 1-6.

9. Willard, S., General Topology, Addison Wesly, London ,1970.

10. Yousif, Y. Y. ; Hussain L. A., Fibrewise Bitopological Spaces, International Journal of Science and Research (IJSR), https://www.ijsr.net/archive/v6i2/v6i2.pdf, February 2017, 6 , 2, $978-983$.

11. Yousif, Y. Y. ; Hussain, L. A., Fibrewise IJ-Perfect Bitopological Spaces, Ibn AlAaitham $1^{\text {st. }}$ International Scientific Conference, IOP Conf. Series: Journal of Physics: Conf. Series 1003 (2018) 012063 doi :10.1088/1742-6596/1003/1/012063, 13-14 December 2017, 1-12.

12. Yousif, Y. Y. ; Hussain, L. A., Fibrewise Pairwise Bi-Topological Spaces, $1^{\text {st. }}$ Scientific International Conference,College of Science, Al-Nahrain University,[DOI. 10.22401/SIC.1.21], 21-22 November 2017,157-165.

13. Yousif, Y. Y. ; Hussain, M. A., Fibrewise Soft Ideal Topological Spaces, Ibn Al-Aaitham

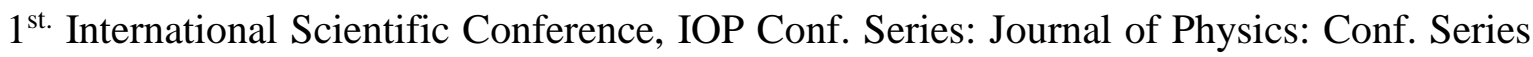
1003 (2018) 012050 doi :10.1088/1742-6596/1003/1/012050, 13-14 December 2017,1-12.

14. Yousif, Y. Y. ; Hussain, M. A., Fibrewise Soft Near Separation Axioms, The $23^{\text {th }}$ Science Conference of College of Education, Al-Mustansiriyah University, 26-27 April 2017,400414.

15. Yousif, Y. Y. ; Hussain, M. A., Fibrewise Soft Topological Spaces, International Journal of Science and Research (IJSR), https://www.ijsr.net/archive/v6i2/v6i2.pdf, February 2017, 6, 2,1010- 1019 .

16. Yousif, Y. Y., Some result on fibrewise Lindelöf and locally Lindelöf Topological spaces, Ibn Al-haitham Journal science, 2009, 22, 3 ,191-198. 
Ibn Al-Haitham Jour. for Pure \& Appl. Sci. 34(3)2021

17. Yousif, Y. Y., Some result on fibrewise Topological spaces, Ibn Al-haitham Journal for pure and Applied science. University of Baghdad - Collage of Education - Ibn Al-haitham, 2008, 21, 2 ,118-132.

18. Zadeh, L. A., Fuzzy sets, Inform. Control ,1965, 8,338-353. 